\title{
REVIEW
}

\section{ANIMAL HEALTH RESEARCH IN SRI LANKA : A REVIEW OF THE PAST, FUTURE PRIORITIES AND CONSTRAINTS}

\author{
M.C.L. DE ALWIS ${ }^{+}$ \\ 7/25, Rosamund Place, George E de Silva Mawatha, Kandy.
}

(Received : 15 December 1997 ; accepted : 02 October 1998)

\begin{abstract}
This paper outlines the historical developments and highlights some milestones and past achievements in animal health research and laboratory services in Sri lanka. It seeks to identify current and future trends and priorities. Lack of local funds and hence the consequent dependence on foreign sources for infrastructure development and training and the high attrition rate of trained manpower are identified as the major constraints.
\end{abstract}

Key words: Animal health, research, veterinary science.

The term 'veterinary science' in a broad sense includes the disciplines of 'animal health' and 'animal production'. The latter, in the NSF's grouping of disciplines is linked with agriculture as 'agriculture and animal husbandry' and includes animal breeding, nutrition and physiology. This communication is restricted to the field of animal health.

\section{Historical developments}

A veterinary service was first established in the British colony, then known as Ceylon, in the year 1884. The first veterinary laboratory service was established in Colombo in the year 1911. Its main function was the diagnosis of animal" diseases. With the amalgamation of the Veterinary Department with the Department of Agriculture (DOA) in 1936, this laboratory shifted to Peradeniya, in 1939. In 1951, it was named 'The Veterinary Research Laboratory'. In response to needs its functions gradually grew. When the epidemic of rinderpest broke out in 1942, this laboratory was assigned the task of producing a vaccine using which, the disease was quickly eradicated. Though named as a 'research' laboratory, no organised research was carried out in the early years, most of the work being confined to the recognition and laboratory confirmation of diseases such as anthrax, black quarter, haemorrhagic septicaemia, foot \& mouth disease, brucellosis and babesiosis in cattle and/or buffaloes and Newcastle disease (Ranikhet) and fowl fox in poultry. With the establishment of the presence of these diseases in the island, vaccines were also produced. It was in the year 1967, that the Veterinary Research Institute (VRI) was set up at Gannoruwa. This institute evolved into a structure which provided for research on both animal health and production. Additionally, it was assigned the task

\footnotetext{
"includes poultry

${ }^{\dagger}$ the author is the former Director of the Veterinary Research Institute
} 
of operating an animal disease diagnostic service and the production and quality control of some animal vaccines.

In the University of Peradeniya, a Department of Veterinary Science was first set up in 1949. The pre-clinical students of this department were serviced by the Medical Faculty in Colombo, in the early years, and later from the Medical Faculty, Peradeniya. Being at different times linked with the Agriculture Faculty and the Medical Faculty, eventually in 1980 it received the status of a separate Faculty of Veterinary Medicine and Animal Science (FVMAS) in the University of Peradeniya. Whilst research on various aspects of animal production is also carried out in departments of animal science set up in several universities, the FVMAS and the VRI remain as the primary seats of animal health research, the former within the university framework and the latter constituting the Research Division of the Department of Animal Production \& Health - an off-shoot of the DOA, carved out in 1978.

\section{Past research and related activities}

In the early years of veterinary research, very little organisation and planning was evident. Areas for research were wide open, and selection was made by the research workers themselves, based upon their own experience, interactions with the field extension service, their training and skills and their own perceptions of priorities. During the first 25 years of its existence, around 400 research publications/communications emerged from the VRI. 'Of these, $45 \%$ were on various aspects of animal health, whilst the balance $55 \%$ (nutrition \& physiology $28 \%$; breeding and reproduction $22 \%$; other $5 \%$ ), covered production. The focus of research in this institute was entirely on agricultural and food animals and this was in keeping with its broad mandate. The FVMAS on the other hand researched on a wide range of subjects, $60 \%$ of its publications being on agricultural and food animals, $15 \%$ on pet animals, a further $1.5 \%$ on. wild life, zoo animals and other exotic species and 10\% on generalised disciplines cutting across species barriers. During the period 1953-1994 nearly 500 research publications/communications arose from work conducted in this faculty. ${ }^{2}$ A cursory glance at the type of research carried out in these two institutions show that the VRI has focussed mainly on research of an applied nature, largely dealing with establishment or improvement of diagnostic and vaccine production techniques, epidemiological studies and such other research that will facilitate control of animal diseases. The university research on the other hand, showed a sizeable component of fundamental studies.

Some specific areas in which significant research contributions have been made are described here. 


\section{Diseases of young animals}

A considerable amount of work has been done to estimate the extent of mortality in cattle and buffaloes at different stages in the age range of birth to one year. The influence of management practices and climatic conditions as predisposing factors as well as specific disease syndromes have been established. The role of gastro-intestinal and respiratory syndromes as dominant causes have been well established. Many species of entero-pathogenic bacterial agents and viruses have been isolated and identified, as well as a variety of helminth parasites. The extensive research conducted at the FVMAS on Toxocara vitulorum a major cause of mortality in young buffalo calves, its life cycle and the mode of acquiring pre-natal infection which led to the development of a simple inexpensive, deworming procedure for buffalo calves, deserves special mention.

The role of respiratory infections in causing mortality in young calves and the role of viral and bacterial agents have been identified in cattle, buffaloes and goats. The information derived from these studies has been useful in improving management practices and introducing health care packages for young animals, in order to minimise losses.

\section{Mastitis}

This is an important disease in both dairy cattle and buffaloes as well as in improved dairy goats. Research on mastitis conducted at the FVMAS has been more of a fundamental nature, attempting to investigate the immune mechanisms in the udder with special attention on the phagocytic activity of milk and blood neutrophils. The VRI has focussed more on the aetiological agents, mode of transmission and the development of control measures. A very simple and economical teat dip solution has been developed, which if used regularly would cause a significant reduction in infection.

\section{Diseases of reproduction}

In the early years, brucellosis was identified as the most important disease accounting for reproductive failure. Over the years various tests have been introduced by the VRI for diagnosis and screening of herds. These include the stained antigen/ whole blood slide agglutination test, tube agglutination test, Rose Bengal plate test, compliment fixation test and the milk ring test. More recently, an ELISA test has been developed at the FVMIAS. Today a range of tests are available for screening on a herd basis to tracking down individual reactor animals and confirmation of diagnosis. 
Using these techniques, the pattern of incidence in the different provinces/agroclimatic zones have been established. This will form the basis for any future control strategies. The VRI also produces the strain 19 live, lyophilised brucellosis vaccine, for controlled use under special circumstances.

Although some serological evidence of leptospirosis in cattle, and buffaloes has been reported a few decades ago, its widespread nature and significance was not realised until a recent survey was concluded at the VRI. This survey which covered a sample of 1500 buffaloes selected. from regions where human leptospirosis was prevalent, indicated that $42 \%$ of test animals were sero-positive against a battery of selected serovars prevalent among humans in Sri Lanka.

These findings with regard to brucellosis and leptospirosis highlight not only their significance as economically important diseases of animals but also as important zoonoses particularly to high risk groups. The potential risk of the exposure of paddy field workers to buffaloes infected with leptospira used for draught work is particularly highlighted.

\section{Contagious diseases of cattle and buffaloes}

Research has been done on several contagious diseases of cattle and buffaloes, mainly with a view to studying their epidemiology, refining diagnostic tests and improving the vaccines used and vaccination programmes with a view to more effective control.

\section{Haemorrhagic septicaemia}

This disease which is endemic in Sri Lanka is a specific form of pasteurellosis, and till the 1970s was listed as the most important killer disease of cattle and buffaloes in Sri Lanka. Research conducted at the VRI was focussed largely on identification and characterisation of the agent, refining diagnostic techniques, epidemiological studies with special reference to the significance of the carrier animal and improvements to the vaccine for greater efficacy, better stability, convenience of field use, and simplicity and economy of production. The implementation of a control strategy in the 1980s utilising the findings from local research, has led to a very significant drop in the herd infection rate as well as the mortality in outbreaks. In recognition of this research the Food \& Agriculture Organisation of the United Nations has designated the VRI Peradeniya as a Reference Centre for Haemorrhagic Septicaemia for the Asia-Pacific Region. 


\section{Foot \& mouth disease}

This was also a disease widespread in Sri Lanka. Early epidemiological research helped to map out the endemic areas where outbreaks originate. Vaccination programmes were carried out based on these findings, so that optimal benefit is derived and the disease is well under control.

\section{Black quarter disease}

This too is a killer disease of cattle and buffaloes and occurs in endemic pockets. Local research carried out at the VRI consisted of epidemiological studies, screening of local isolates of the causative organism Clostridium chauvoei for selection of a suitable vaccine seed and development of improved vaccine production procedures. The result has been the development of a vaccine as effective as any imported commercial vaccine.

\section{Helminthiasis}

A wide range of helminth parasites have been identified and a check list has been prepared. Those helminth worms that cause significant pathological effects have been recognised and their life cycles and epidemiological information documented for the various agro-climatic zones. Strategic deworming schedules are now being formulated for each species and region using such information. The prevalence, pathology and pathogenesis of cerebro-spinal nematodiasis (CSN) caused by the migration of larvae of a setarial worm of cattle into the nervous tissue of goats has been studied and documented. CSN is a menace to goat farmers in some districts. Control strategies based on these studies are being developed.

\section{Tickborne diseases}

The presence of several tickborne haemoprotozoan diseases of cattle and buffaloes has been established. Numerous diagnostic tests ranging from simple stained blood smear examination to sophisticated serological tests such as the fluorescent antibody technique have been developed and refined from time to time. Whilst the direct economic losses due to diseases such as babesiosis have been well established, the actual, often indirect and insidious losses due to other diseases such as anaplasmosis, theilleriosis, trypanosomiasis and ehlichiosis is yet uncertain, though their prevalence is known.

The development of a vaccine against the bovine babesiosis (caused by $B$. bovis and $B$. bigemina) has passed through several stages and presently a safe and effective irradiated live vaccine is available. 


\section{Poultry diseases}

In the early years of veterinary research, two diseases, Newcastle disease (Ranikhet) and fowl pox were considered to be of economic importance and hence, some research was carried out on them. These are viral diseases controlled by vaccination. Much of the work has been in the areas of vaccine development and improvement with special reference to potency and stability and the formulation and evaluation of the efficacy of field vaccination schedules. In more recent years, with the emergence of other viral diseases, sero-epidemiological surveys were carried out to establish the prevalence of a range of diseases. Special attention has now been given to isolation, identification and characterisation of the strains of viruses responsible for these diseases in Sri Lanka, and their comparison with standard vaccine strains. A foreign funded project also led to the development of an effective fowl cholera vaccine, protective against local strains and which is comparable with any imported commercial vaccine.

\section{The Role of NSF (NARESA)}

It was reported that up to the 1980 s in the government research institutions in the agriculture sector, which includes the VRI, over $80 \%$ of the annual recurrent budget provided by the Treasury was used up for maintaining the establishment. Only a small percentage of funds was available for operational research. A considerable amount of supplementary funding for specific research projects is therefore obtained as grants from external sources, both within and outside Sri Lanka. NSF (NARESA) is an organisation. which has always been a steady and continuous source of such supplementary research funding. Overseas funding sources such as the FAO, British ODA, World Bank, Australian Centre for International Agricultural Research (ACIAR) etc., provide similar funding but for specific periods and for specific areas of interest only. NARESA would, on the other hand fund any research project which fell within its research priorities in the given field, based on an evaluation of each proposal on its own merit, by an Expert Committee.

Since its inception NARESA has awarded around 65 research grants both to the VRI and the FVMAS for projects in animal health. The role played by NARESA in the SAREC/NARESA buffalo research programme deserves special mention. Under this programme, Swedish funds which were provided for research on the water buffalo were channelled through NARESA, which undertook the responsibility of appraisal of research proposals, monitoring of performance and in general administering the programme. To assist in these tasks, an advisory committee was set up. A total of 71 projects were approved for funding by SAREC. Of these 69 
were awarded and 60 (87\%) were successfully completed. Nine of these projects were in the field of breeding and reproduction, 14 in nutrition and physiology and 19 in buffalo health. The balance 20 projects covered inter-disciplinary areas which included socio-economics of buffalo husbandry, utilization, management and infrastructure development. Six Ph.D degrees and seven M. Phil. degrees were awarded to scientists who used work of this programme wholly or partly for their theses. The programme which was operative during the period 1983-95 was worked out in two phases. In phase I, out of an allocation of Rs. 8.3 million, an expenditure of $92 \%$ was recorded whilst of Rs. 19.3 million allocated to phase II, 76\% was expended. This included some inputs from the projects for the strengthening of the infrastructure in the eight participating institutions, in order to facilitate project work. The main institutions were the FVMAS and the VRI with a few projects scattered in six other institutions.

\section{Current and Future Trends in Animal Health Research}

The overall objective of research in the livestock sector is to increase production of livestock products (milk, meat, eggs), so as to increase the per capita availability of these items, to adequate levels, in order to uplift the nutritional status of the Sri Lankan population, whilst at the same time, increase the income levels of the producer farmers. These objectives have to be achieved in a scenario characterised by (a) diminishing land resources available for livestock farming (b) increasing competition between man and livestock for cereal food.stuff, and (c) increasing human population. Research must, therefore, be geared towards (i) developing stock with a superior genetic production potential (ii) developing livestock feeding systems based on freely available feed resources, with special attention to crop residues and agro-industrial by-products (iii) improving the reproductive efficiency of livestock (iv) eliminating or minimising losses due to diseases, including losses due to mortality, impaired growth, lowered production and reduced fertility resulting from disease and (v) developing intensive management systems using minimal land with special attention to integrating livestock with crops.

Taking into consideration the above situation, the Council for Agricultual Research Policy (CARP) has developed a set of national priorities for research in the livestock sector. This list was prepared by interaction with a wide spectrum of persons associated with the livestock industry, consisting of livestock farmers, farmer organisations, representatives from the livestock processing and marketing sector, feed manufacturers, livestock scientists and teachers and also administrators and policy makers. The interaction was made effective through a series of workshops. Briefly, the mechanism of identification of priorities consisted of (a) identifying the problems constraining increased livestock 
production, (b) sieving out the problems that can be resolved by research and (c) working out the cost/benefits of interventions to solve these problems. This list of national priorities in animal health and production consist of 44 research thrusts and 16 of these relate to animal health.

A breakdown of this list on a species/industry-wise basis, and as applied and basic research thrusts is shown in Table 1.

Table 1: National research thrusts in the livestock sector.

Applied Research

$\begin{array}{ll}\text { Poultry } & 08(01)^{*} \\ \text { Cattle \& Buffalo } & 13(04) \\ \text { Goats \& Sheep } & 06(02) \\ \text { Pigs } & 02\end{array}$

Basic Research

Figures within brackets indicate the number of animal health thrusts.

The specific projects under each thrust and the cost of research, costs and benefits to farmers adopting the research innovations and the potential contribution at national levels have been worked out. This information is now available for the evaluation of any research proposal. This exercise and its product, confines itself to agricultural animals only.

\section{Infrastructure for Veterinary Research}

In the foreseable future, the institutions that will engage in animal health research will continue to be the VRI and the FVMAS. The VRI is functionally linked to a network of regional diagnostic laboratories manned by personnel with a basic postgraduate training in pathology, parasitology and microbiology. These persons who have close links with extension staff are ideal research collaborators.

\section{Research facilities and constraints}

Both the VRI and the FVMAS are well equipped for basic pathology (including clinical pathology), bacteriology and virology (including the isolation and characterization of important pathogenic bacteria and viruses). Facilities are also available for serological work (including modern serological techniques). Nuclear and nuclear-related techniques are popularly used in animal health work. Radio immunoassay (RIA) technique has been established at the FVMAS and is mostly used in hormone estimations. The ELISA technique is now popularly used for diagnosis of a wide range of diseases and in sero-epidemiological work. Polyacrylamide gel eletrophoresis (PAGE) and immunoblotting 
techniques are currently used as research tools and the VRI is in the process of introducing more sophisticated molecular techniques such as Polymerase chain reaction tests (PCR) and PFGE (Pulse Field gel electrophoresis). At the VRI, spectrophotometry, atomic absorption spectrophotometry and high pressure liquid chromatography (HPLC) are widely used for the estimation of minerals and vitamins. These include $\mathrm{Ca}, \mathrm{Mg}, \mathrm{Cu}, \mathrm{Zn}, \mathrm{Mn}, \mathrm{Na}, \mathrm{K}, \mathrm{P}, \mathrm{Co}$, Vitamins B12, A and $\mathrm{E}$.

\section{Funding}

In order to augment financing through the consolidated fund, moderate supplementary funding is available through bodies like NSF and CARP. Funds from foreign agencies are usually utilised when infrastructure development and introduction of new technologies are required. The University has its own scheme of research grants. Routine research funding has not been a major constraint but large volume of funds required from time to time for upgrading the infrastructure are not easily found.

\section{Manpower}

The current availability of trained manpower in the two institutes is shown in. Tables 2 and 3

Table 2: Trained manpower at the Faculty of Veterinary Medicine and Animal Science, University of Peradeniya (1997).

\begin{tabular}{l|c|c|c}
\hline Field of Specialisation & Ph.D. & M. Sc. & Basic degree \\
\hline $\begin{array}{l}\text { Anatomy, Physiology \& } \\
\text { Biochemistry }\end{array}$ & 3 & 3 & 5 \\
Pathology & 3 & - & 1 \\
Parasitology & 1 & - & 1 \\
Microbiology & 2 & - & 2 \\
Pharmacology & 1 & - & - \\
Public Health & - & - & 2 \\
Medicine & 2 & - & - \\
Surgery & 3 & - & 1 \\
Reproduction & 1 & - & - \\
\hline
\end{tabular}

Includes those undergoing postgraduate training. 
Table 3: Trained manpower at the Veterinary Research Institute (1997)

\begin{tabular}{|c|c|c|c|}
\hline Field of Specialisation & Ph.D. & M. Sc. & Basic degree \\
\hline $\begin{array}{l}\text { Animal breeding and } \\
\text { Reproduction }\end{array}$ & 2 & - & 3 \\
\hline Animal Nutrition & 2 & 1 & 2 \\
\hline Farming Systems & - & - & 4 \\
\hline Parasitology & - & 3 & - \\
\hline Bacteriology & 2 & --- & 2 \\
\hline Virology & - & - & 4 \\
\hline Pathology & 1 & 1 & - \\
\hline Diagnostic Services & 1 & 2 & 3 \\
\hline Vaccine Production & 1 & - & 4 \\
\hline
\end{tabular}

"Includes those undergoing postgraduate training. This table includes those in animal production disciplines as well.

Two major constraints are encountered in human resource devejopment in both institutions. Firstly neither institute has funds of their own for postgraduate training; and are thus almost totally dependent on foreign sources. Secondly, there is a high attrition rate of trained personnel. Whilst both institutes lose personnel who go abroad in search of greener pastures, a significant number of VRI personnel leave their research positions to join the universities. This is encouraged by the wide disparity in renumeration and promotional prospects between the two institutions. Further, the VRI scientists belong to the Animal Production and Health Service, where fixed cadres exist in each grade. Thus, however meritorious an officers performance may be, his/her promotion depends on the availability of a vacancy in the next higher grade.

The number of new Universities that have sprung up has aggravated this problem. On some occasions, Universities have indiscriminately absorbed inappropriately qualified personnel, who are enticed purely by a higher salary. An instance is on record, where a qualified virologist from the VRI was absorbed to a University to teach animal husbandry leaving the VRI with 
no virologist at all. During the past 25 years, the VRI has lost 23 postgraduate trained personnel and the FVMAS has lost 16 of its staff members during the period 1980-1995. This situation has made it difficult to develop a planned manpower development programme and to maintain an optimum manpower requirement.

Particularly at the VRI, the few perks that exist are linked with administrative positions, and scientific personnel are relatively disadvantaged in comparison with comparable personnel elsewhere. Thus trained scientists rarely remain in research for sufficiently long periods to acquire experience and maturity in their own fields. This situation is not peculiar to animal health scientists and is a matter which needs to be looked into in the future, if the contribution of these scientists towards the development effort is to be maximised.

\section{References}

1. Anon (1992). Twenty Fifth Anniversary (1967-1992) Publication. Veterinary Research Institute, September 1992.

2. Anon (1995). Research Directory 1953-1995. University of Peradeniya, Faculty of Veterinary Medicine and Animal Science, December 1995. 